\title{
Microscopy Career and How It Defined My Choices
}

\section{Craig Henry}

Thermo Fisher Scientific, Hillsboro, Oregon, United States

Growing up in Rochester, New York, my love of science started when I was young. The city was home to companies such as Eastman Kodak Company, Xerox, and IBM, which helped inspire my interest in scientific fields. During high school, I often pondered which area of science I liked the most. This ultimately led me to take majority of the science courses and to participate in a high school internship program at Eastman Kodak Company.

I learned that my greatest interest was in Chemistry, specifically with analytical instrumentation. The proverbial phrase 'the apple doesn't fall far from the tree' held true, since my father was a trained and practicing chemist. An enthusiasm for science was the centerpiece of both my high school and college careers, though by college my passion was further refined to focus on analytical chemistry. I observed that puzzles and analytical chemistry are very similar: the correct result is determined from experimentation, and in analytical chemistry this validation is conducted primarily through spectroscopy.

How does one determine if they are ready for Industry? Securing an internship is one of the best methods to gain work experience during one's education. For me, this included both high school and college internships at Eastman Kodak Company. In the course of these work experiences, I supported a microscopy group preparing TEM sample using mechanical processes and later was able to a FIB TEM lamellae with the DualBeam ${ }^{\mathrm{TM}} 620^{1}$. Beyond acquiring enhanced technical skills, these internships allowed me to gain valuable communication skills and how this is adjusted to different audiences within the corporate structure.

At the time, the DualBeam 620 product was new to the industry. Since that internship coincided with my senior year at college, I naturally asked myself, "Do I join the Industry or continue in Academia?" The answer was simple: I thoroughly enjoyed microscopy and was motivated to further expand both my technical knowledge and business experience within industry. The rest is history, as I have been able to build a successful career within Thermo Fisher Scientific (formerly FEI Company).

\section{References}

1 Daniel Phifer, Brandon van Leer, David Wall, Anthony Burgess (2015, May) Fast, Flexible Sample Preparation with DualBeam ${ }^{\mathrm{TM}}$ Instruments, Presentation at the 49th Annual Scientific Meeting of ISM Bar-Ilan University, Ramat Gan 